Heredity. By J. Arthur Thomson. Second edition. Pp. xvi+627. (London: John Murray, 19i2.) Price $9 s$. net.

IN the present edition of his book, the original edition of which was reviewed in NATURE for August 20, I908 (vol. lxxviii., p. 36r), Prof. Thomson has included references to some of the new discoveries that have been made in the last five years in the branch of biology with which the volume is concerned.

\section{An Elementary Historical Geography of the British}

Isles. By M. S. Elliott. Pp. $\mathrm{x}+\mathrm{I} 7^{2}$. (London: A. and C. Black, 19r3.) Price rs. $6 d$.

THIs little book shows very convincingly how profoundly the geography of a country can influence its history; and it serves to demonstrate also the
LETTERS TO THE EDITOR.

[The Editor does not hold himself responsible for opinions expressed by his correspondents. Neither can he undertake to return, or to correspond with the writers of, rejected manuscripts intended for this or any other part of NATURE. No notice is taken of anonymous communications.]

\section{lceberg Melting.}

I HAVE pleasure in sending you a photograph of the iceberg around which we obtained the isothermal lines published in NaTuRE of December 12, 1912. I did not make an instrumental survey of this berg, but it was larger than the average of those met with in the Strait of Belle Isle. We sighted more than 200 bergs during our trip, and made traces of many of them. Invariably the temperature rose on the approach to a berg. Sometimes a small fall of tem. perature resulted abeam of the berg, but the rise of

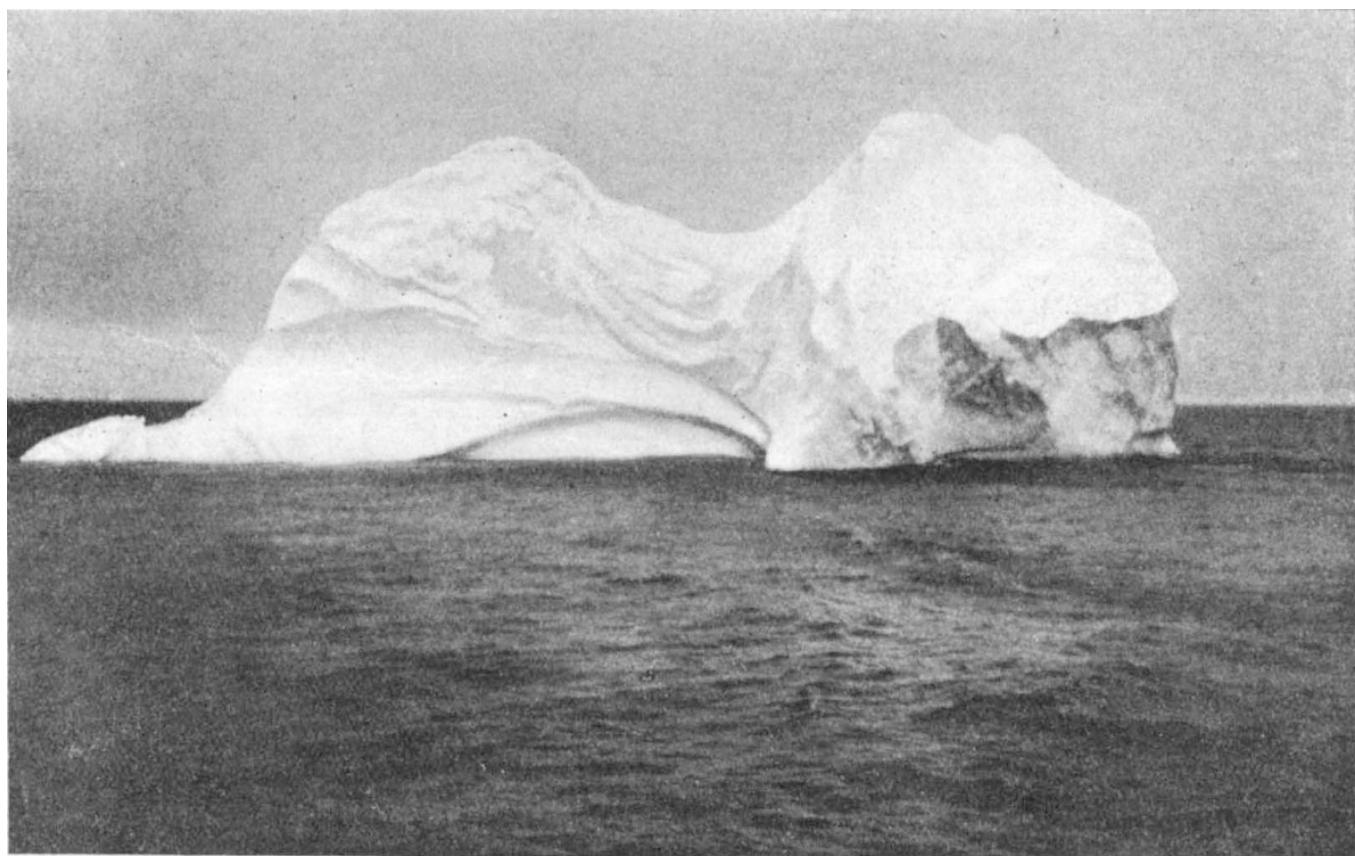

FIG. x.-Iceberg used for the purpose of studying the isothermal lines published in the issue of NATURE for December 12, rgr2.

necessity of a good knowledge of geography for teachers of history. The volume may be recommended as suitable for supplementary reading for boys and girls in secondary schools who are studying history or geography. The book is well illustrated and contains numerous helpful maps.

\section{The Interpretation of Radium. By F. Soddy. Third edition. Pp. xvi 284 . (London: John Murray, 1912.) Price $6 s$. net.}

THE general characters of this work were given in the review of the first edition which appeared in the issue of Nature of May 27, rgog (vol. lxxx., p. 368). In the present issue $\mathrm{Mr}$. Soddy has included the latest and most complete data available, and those new discoveries for which there is trustworthy evidence. A new final chapter upon the thorium and actinium series has been added.

NO. 2260 , VOL. 90] temperature was the one characteristic effect. The two other photographs [not reproduced] I send you illustrate the fantastic shapes seen in ice. I wish it were possible to furnish in some way an idea of the wonderful colouring, but I am totally unable to do so.

In the "swimming moose" you can see the dangerous overhanging ridge, which is caused by the underwater melting and the lapping of the warmer water waves against the ice. This ridge is always found in bergs which have not recently turned over. In the records which Mr. King was able to get for me in 19ro, besides the rise of temperature, a fall of temperature was obtained, when the ship approached the various icebergs, with the exception of one. These bergs were all floating in the main arctic current off the eastern coast of Labrador. In the. Fight of my recent work I feel sure that the drop in temperature was due to the influence of the cold current in which the iceberg was floating. These cold currents exist in the main arctic current, whether ice is present or sot, but the effect of the presence of the ice is to elevate the temperature slightly. 